\title{
TÉCNICA, ARTE E INDÚSTRIA CULTURAL SEGUNDO ADORNO
}

Francisco Rüdiger*

SÍNTESE - Partindo de um exame mais cuidadoso e de uma leitura menos linear das fontes, 0 artigo procura mostrar que as concepções adornianas a respeito da arte na era da técnica, embora críticas, revelam uma abertura dialética, não se deixando prender a dogmas e preconceitos, conforme pretendem seus adversários.

PALAVRAS-CHAVE - Adomo - estética; art indústria cultural; art - mídia.
ABSTRACT - Through a more carefull analysis and a less linear lecture of the textual sources, this article aims to prove that Adorno's concepts on the aesthetics situation of arts in the age of techniques are free from de theoretical dogmas and elitist prejudices that habe been imputed on them by their antagonists.

KEY WORDS - Adorno - aesthetics; arts culture industry; arts - media.

Tornaram, os adversários da teoria crítica, corrente o juizo de que ela se baseia em uma concepção elitista da cultura e alimenta fortes ressentimentos em relação às formas de arte tecnológicas. Para eles, Adorno opõe de maneira preconceituosa e mecânica a "forma alta" à "forma baixa" (popular) da cultura, considerando a primeira mais valiosa do que a segunda, na medida em que enquanto aquela, segundo a leitura desses autores, contém um potencial cognitivo crítico, essa não apenas conduz a um estado de paralisia ideológica como resulta na degradação da alta cultura.

Resumidamente, pode-se dizer que o ponto comum entre os defensores deste juízo é o entendimento da critica à indústria cultural como expressão de

\begin{abstract}
"um aristocratismo cultural que se nega a aceitar a existência de uma pluralidade de experiências estéticas, uma pluralidade de modos de fazer e usar socialmente a arte. Estamos diante de uma teoria da cultura que não só faz da arte seu único paradigma, mas a identifica com seu conceito: um conceito unitário, que relega a simples e alienante diversão qualquer tipo de prática ou uso da arte que não possa derivar-se daquele conceito e que termina fazendo da arte o único lugar de acesso à verdade da sociedade."1
\end{abstract}

A proposição não passa sem problema na medida em que, vendo mais de perto, os frankfurtianos criticaram a cultura em todas as suas formas de expressão.

* Doutor em Ciências Sociais e professor-adjunto da PUCRS.

1 BARBERO, J. M. De los medios a las mediaciones. México (DF): G. Gilli, 1987, p. 54.

\begin{tabular}{|l|l|l|l|l|l|}
\hline VERITAS & Porto Alegre & v. 43 & $\mathrm{n}^{0} 2$ & Junho 1998 & p. 399-411 \\
\hline
\end{tabular}


Em seu modo de ver, "a arte autônoma não está completamente isenta do insulto autoritário da indústria cultural". ${ }^{2}$ A polêmica se dirige tanto àqueles que defendem a arte pela arte, quanto àqueles que defendem seus vários subprodutos mercadológicos. "A crítica do kitsch nada deve descurar, mas, enquanto tal, avança pela arte adentro", escreve Adorno (Estética, p. 346).

“As platitudes a respeito do progresso espiritual, particularmente da arte, procedem desde o princípio contra a vontade da maioria, possibilitam aos inimigos mortais de todo o progresso entrincheirarem-se atrás daqueles que, realmente sem ter nenhuma culpa, são excluídos dos meios para expressar vitalmente seus próprios problemas." 3

Segundo a visão do pensador, também as obras de arte são uma forma de ideologia pois seu modo de ser tem como condição o fetichismo da mercadoria. Hoje há que se opor à arte fácil e não menos porém à ambiciosa, pois ambas são faces da reificação. Como diz $\mathrm{M}$. Jay, os comentários que o autor fez contra a cultura de massa também se dirigem contra boa parte da chamada alta cultura porque, em seu modo de ver, "toda cultura, elevada ou não, contém um momento de barbárie".4

Stravinski e Sartre lograram criar obras de arte autônomas e bem sucedidas em plena era da indústria cultural mas isso não as isenta de uma análise crítica pois, em última instância, pertencem a um mundo em que nada mais se situa fora do seu contexto de culpabilidade e, por isso, impede-nos de "criticar a indústria da cultura sem ao mesmo tempo criticar a arte". ${ }^{5}$

$\mathrm{Na}$ verdade, a pretendida distinção entre cultura erudita e popular, arte e diversão, é falsa e verdadeira do ponto de vista histórico. A partilha é falsa porque ambas dependem do mercado, emergem dentro de certa alienação, embora sob diferentes máscaras. Enquanto a primeira refugia-se no estilo, a segunda procura resguardar-se através da popularidade. No entanto, a divisão conserva uma parcela de verdade porque enquanto a cultura popular tende a se esgotar na diversão, a pesquisa à qual a outra se liga tende a conferir-lhe uma relativa liberdade em relação aos ditames da sociedade.

"O conteúdo de verdade das obras de arte que é também a sua verdade social tem como condição o seu caráter fetichista mas esse pode ser distinguido do puro e simples fetichismo da mercadoria" (Estética, p. 255-256).

Conforme Adorno nota em sua polêmica com Benjamim, tanto a arte leve quanto a arte séria carregam " o estigma do capitalismo, ambas contêm elementos de troca; ambas são as metades arrancadas da liberdade inteira, que não se deixa somar a partir delas: sacrificar uma à outra seria romântico, seja o romantismo

2 ADORNO, T. Teoria estética. São Paulo: Martins Fontes, 1982, p. 29. Doravante, a obra será citada, no corpo do texto, como Estética.

3 Adorno, T. The culture industry (Editado por Jay Bemstein). Londres Routledge, 1991, p. 111. Doravante, o livro será citado, no corpo do texto, como Culture industry.

4 JAY, M. Adorno. São Paulo: Cultrix, 1984, p. 108. A proposição em foco, conforme se sabe, provém de Benjamin.

5 ADORNO, T. Aesthetic theory. Londres: Routledge, 1984, p. 39. 
burguês da conservação da personalidade e da magia, seja o anarquista, da confiança cega na autonomia do processo no processo histórico"6

As experiências movem-se como uma só coisa que, todavia, não deveria nos fazer esquecer ou perder de vista "a diferença entre utilizar uma vulgar canção sentimental, na qual nada há para compreender, como pantalha para as mais diversas projeções psicológicas, e compreender uma obra de modo a submeter-se a sua própria disciplina" (Estética, p. 296).

O contraponto entre arte à indústria cultural é ideologia, encontrando seu conteúdo de verdade apenas em algumas obras de arte moderna. A produção artística modernista é a única que realmente se opõe ao consumo estético massificado. Durante séculos houve apenas as obras de artes artesanais. As expressões artísticas (pintura, música, teatro) tinham um caráter único, ligado ao momento de contato com a obra em sua originalidade. $O$ progresso das forças produtivas não só ensejou os meios para reproduzi-las (cinema, rádio, vídeo) como levou ao aparecimento de novas formas (filme de ficção, folhetim, música eletrônica), conferindo ao conjunto a condição de obras de arte tecnológicas.

0 conceito de arte nova (moderna) refere-se às (poucas) obras que procuram resistir à liquidação dos valores estéticos que ocorre junto com este fenômeno, na medida em que este, conforme a teoria crítica, se confunde com o processo de conversão da cultura em mercadoria. A condição não requer que sejam artesanais. A circunstância de serem conhecidas ou mesmo produzidas através de gravações, filmes e outros meios técnicos, em si mesma, é totalmente irrelevante, pertencendo às condições de nosso contexto histórico. A caracteristica distintiva é rejeitar o caráter de fetiche da mercadoria, revelar um momento de oposição à estrutura social dominante, contrapondo-se em alguma medida ao espírito da cultura de consumo.

A transformação da cultura em mercadoria que se esconde por trás dos progressos dos meios técnicos privou a arte de sua relativa autonomia. Os estímulos estéticos passaram a ser empacotados de acordo com as médias de gosto descobertas no mercado. "A satisfação sensorial, por vezes punida de modo ascético e autoritário [no passado], tornou-se historicamente inimiga direta da arte, na medida em que a eufonia dos sons, a harmonia das cores, a suavidade tornaram-se kitsch e marcas distintivas da indústria cultural" (Estética, p. 307).

A consciência estética todavia não sucumbiu de todo diante desse processo, inclusive onde os artistas não tomaram o caminho da resistência. As vanguardas realmente sérias se negaram a ser coniventes com o mercado e a abrir mão de sua autonomia, conforme exigido pelos novos aparatos de publicidade.

\footnotetext{
"Cocteau não foi o primeiro a apontar que, a partir do impressionismo, o desenvolvimento da nova pintura só poderia ser entendido em sua relação com a fotografia. Em termo de estruturação ótica, a pintura torna-se aquilo que escapa à técnica fotográfica e, ao mesmo tempo, torna-se uma resistência contra a metamorfose do mundo em seu decalque fotográfico, que hoje se vai completando. Análoga é a relação da música artística com a música ligeira [...] na medida em que, para não fazer o jogo do rebanho geral, se volta contra o ouvinte, contestando as costumeiras concepções de imediatez e naturalidade" (Sociologia, p. 152).
}

6 ADORNO, T. Sobre Walter Benjamin, p. 142. 
A estratégia adotada pela arte moderna, noutros termos, foi reclamar a reificação para seu próprio trabalho a fim de que, na falta de outra opção, esta surgisse de seu próprio impulso, ao invés de lhe ser imposta pela sociedade. A produção estética que não quis ser cooptada passou a ser desestetizada. Os artistas não tiveram outro recurso senão despojar-se da aparência do belo e do agradável e, tendo em vista sua nova forma de atuação, colocar-se à distância dos meios de difusão que, noutro contexto, talvez pudessem aproximá-las da população (Estética, p. 272).

A contraposição entre arte nova e indústria cultural que se ensaia assim todavia não se trava no plano da técnica.

"O rádio viu-se privado em boa parte de seu direito mais legítimo, que seria transmitir às residências particulares uma música que, devido à sua própria estrutura, seguisse os princípios mais apropriados àquelas condições de escuta: isto se explica sociologicamente."7

Para Adorno, o conceito de arte moderna deve ser reservado aos procedimentos técnicos que em seu próprio modo de ser convertem as obras em imagem da sociedade capitalista e não àqueles da produção em massa que querem servir a esta mesma sociedade. A perspectiva não significa porém que essas obras não possam se valer da técnica, porque nada obsta para que dela se utilizem. Durante vários anos, o pensador sustentou que as técnicas artísticas e industriais não tinham o mesmo sentido em nosso contexto histórico.

Adorno supunha que pelo fato de a criação e emprego das novas técnicas de reprodução serem expressão de uma era em que o progresso técnico se encontra fora de controle social e, assim, as pessoas estarem sujeitas à técnica, essas técnicas não podiam ser veículos artísticos autônomos. $O$ cinema e o disco, para ficar neles apenas, eram antes de mais nada formas do recém estabelecido imperialismo cultural da tecnologia.

Para ele, a tecnificação da arte era um subproduto do "fascínio que exerce o progresso ambivalente que, a expensas do possivel, considera seus supostos efetivos como garantia de irrefutabilidade - para neles se acantonar; empurra-nos para o estado de coisas existente e, assim, converte-se secretamente em regressão, para a qual tende por ora o conjunto da sociedade industrial tardia". ${ }^{8} \mathrm{~A}$ possibilidade de dessacralizar as obras de arte escondida nos meios técnicos, reproduzindo-as da maneira menos espiritual possível, fora virtualmente neutralizada pela sua exploração econômica.

As tecnologias de comunicação surgiram e passaram a atuar no bojo da expansão das relações mercantis e, assim, viram-se impedidas de ensejar a criação de formas de arte adequadas às suas condições materiais e tecnológicas. "O cinema e o rádio foram determinados artisticamente pelos que chegaram primeiro e descobriram o aspecto comercial das novas técnicas." ${ }^{\text {O }}$ Os esforços no sentido

7 ADORNO, T. II fido maestro sostituto. Turim: Einaudi, 1969, p. 270. Doravante, a obra será citada, no corpo do texto, como Maestro.

8 ADORNO, T. Musica y tecnica, hoy. In: AXELOS, K. et al. El arte en la sociedad industrial. Buenos Aires: Alvarez, 1973, p. 149 .

9 ADORNO, T. El cine y la musica. Madri: Fundamentos, 1976, p. 66. Doravante, a obra será citada, no corpo do texto, como Cinema. 
antes referido abortaram, e não houve outra opção senão se curvar à ratio comercial. $\mathrm{O}$ caminho seguido foi, em regra, a adaptação de velhas formas de arte. $\mathrm{O}$ rádio e o disco, por exemplo, não evocaram nenhuma forma nova de música, limitando-se a veicular o material sonoro criado fora de seu âmbito. ${ }^{10} \mathrm{O}$ cinema logrou criar a figura do filme de ficção mas, via de regra; este tomou como modelo a novela burguesa do século XVIII.

Resumidamente, Adorno defendeu que a produção destinada aos meios de difusão em massa era moderna pelo fato de aceitar os esquemas industriais e mercantis. A novidade não estava nos bens por ela criados mas nas últimas técnicas descobertas para veiculá-los e seus respectivos instrumentos propagandisticos. Entretanto isso não o impediu de reconhecer em seus escritos tardios que é possivel produzir esteticamente com as técnicas industriais porque, em última instância, as mesmas forças humanas de produção atuam por detrás das descobertas científico-tecnológicas e da técnica puramente artística.

\footnotetext{
"O perigo do feiticismo tecnológico e da pesquisa diletante estranha ao verdadeiro significado da coisa não pode ser substancialmente deplorado como uma mera aberração, dado que este perigo é um aspecto necessário e inseparável da presente crise do sentido musical e do conjunto dos fatores estéticos" (Maestro, p. 264).
}

As prédicas em favor da cultura contra a técnica são tão reacionárias hoje como o foram no passado, porque "já faz muito tempo que a técnica e os materiais disponiveis vêm inspirando à fantasia, a mesma fantasia que os pedantes defendem contra ela [isto é, a tecnologia]". Os procedimentos eletrônicos e o filme são meios através dos quais sem dúvida se pode criar obras originais. Tecnologicamente, constituem, tanto um quanto o outro, "o processo mais progressista existente porque possu[em] [em princípio] o máximo de liberdade em relação ao material que lhe chega pronto e [em tese] apenas aguarda ser descrito e transmitido: a produção e a reprodução coincidem, produzindo-se somente o que se pode ver na tela [e nos alto-falantes]" (idem, p. 273-274).

Conforme explica o pensador, "o antagonismo no conceito de técnica como de algo de intra-esteticamente determinado e de um desenvolvimento exterior às obras de arte não pode conceber-se de modo absoluto". A diferença deve ser mediatizada. Precisamos reconhecer que é "possivel produzir artisticamente a partir da natureza específica de meios de origem extra-artística" (Estética, p. 46) assim como valer-se de procedimentos artísticos para corrigir e ultrapassar as técnicas extra-artísticas imanentemente (idem, p. 177). A construção e a montagem são meios artísticos que expressam a era da técnica e que, no entanto, podem" desembocar numa forma estética ainda desconhecida, cuja organização racional anuncia a supressão de todas as categorias da administração e de todos os seus reflexos na arte" (idem, p. 252).

10 ADORNO, T. "The form of the phonograph record". In: October, 55 (56-61) 1990, p. 56-57. Stravinski, Duchamps e Breton, entre outros, cogitaram essa possibilidade que, todavia, revelou-se improdutiva socialmente. Cf. Kahn, D. \& Whitehead, G. Wireless imagination. Cambridge (MA): MIT Press, 1992. 
A perspectiva serve de ponto de partida para fazermos uma reavaliação do problema da própria indústria cultural, lembrando-se em primeiro lugar que sua oposição à arte nova não deve ser entendida de maneira dogmática mas crítica e dialética.

Aparentemente, Adorno não queria jogar uma arte contra a outra, como pretendem seus detratores. A postura não lhe caía bem porque em seu modo de ver convergia com a dos advogados da indústria cultural. A suposição de que ambas podem conviver lado a lado e cada um de nós pode escolher à vontade seu partido é produto de um pluralismo indigente e expressão de uma sociedade onde o espírito já não está preso a nenhum conceito apenas como ideologia. Na verdade, os fenômenos encontram-se integrados numa unidade, constituindo uma totalidade concreta e necessária, "que não se move senão em constante contradição". ${ }^{11}$

Em termos teóricos, a preocupação do autor era antes esclarecer criticamente esta situação, especialmente a maneira como suas tensões, constitutivas para a obra de arte moderna, se tornaram tão profundas no capitalismo avançado, a partir da integração forçada das esferas da cultura superior e arte bárbara promovida pela indústria cultural.

A relação entre as esferas da arte leve e arte superior é mediada uma pela outra e está sujeita ao processo histórico. Significa que ela comporta a possibilidade de superação. A comprovação se encontra na maneira como vem se tentando conciliá-las ao longo da história e, às vezes, chegou-se mesmo a obtê-la com sucesso. Wolfgang A. Mozart, por exemplo, manejou com tal maestria suas oposições que, pode-se dizer, chegou ao ponto de superá-las em A Flauta Mágica. Werther, de Goethe, embora sem tendência e ainda que sem o nomear, expressou um sentimento de toda a humanidade. E Collete escreveu narrativas profundas sem se incomodar com o final onde a heroína frígida encontra o prazer nos braços do esposo legitimo.

Atualmente, porém, "a possibilidade desse equilíbrio esvaeceu e as tentativas de amálgama - a exemplo dessas assumidas por compositores diligentes no tempo em que o jazz se tornou mania, permanecem improdutivas". ${ }^{12}$ Entretanto a crítica não pretende proibir a procura da referida superação nem deveria vedar a possibilidade dela ser encontrada, situando-nos por um momento além da indústria cultural. "Só mutilado é que o vulgar representa o plebeu posto de lado pela chamada arte nobre" (Estética, p. 268).

A contraposição entre cultura e barbárie, arte e distração barata, sempre existiu enquanto expressão da divisão da sociedade e, se passou a ser vista com maus olhos com a ascensão da era moderna, não deixou de indicar uma verdade a respeito da sociedade. A tentativa de fundi-las numa sintese mercantil representa sua falsificação. Noutros termos, o problema com a indústria cultural é que ela, "em detrimento de ambas, força a reunião das esferas da arte superior e da arte inferior, separadas há milhares de anos. A seriedade da arte superior é destruida através da especulação sobre sua eficácia; a da inferior é perdida com a imposição

11 ADORNO, T. Disonancias. Madri: Rialp, 1066, p. 26.

12 ADORNO, T. “On the social situation of music". In: Telos, 35 (128-164) 1978, p. 160. 
de coações civilizadoras à resistência rebelde que carregava consigo quando o controle social ainda não era total" (Culture Industry, p. 93).

A subordinação da produção ultural erudita aos esquemas da indústria cultural não significou a democratização da cultura, mas a supressão do projeto contido em seu conceito. "Os conteúdos objetivos da formação cultural, coisificados como mercadorias, sobrevivem à custa de seu conteúdo de verdade e de suas relações vivas com o sujeito vivo, o que de certo modo equivale à sua definição". ${ }^{13}$

Entretanto, a cultura popular também saiu perdendo neste percurso. O desenvolvimento industrial tende a privá-la da espontaneidade, transformando-a em artigo de consumo. Aparentemente, os primeiros filmes de animação eram sobretudo fantasias populares que tentavam dar uma segunda vida aos mutilados pelo progresso, antes de se tornarem um meio de habituar os sentidos ao ritmo da vida moderna; e o jazz foi em sua origem uma expressão do lumpesinato negro que terminou sendo cooptada pela indústria e privada dos seus aspectos críticos. A racionalização a que a arte bárbara foi submetida colocou-a na dependência do processo de divisão do trabalho: desde então, o caçador de talentos, o produtor, o divulgador, o vendedor etc. dirigem e controlam seus impulsos.

O principal problema porém provém do fato dessa sintese perpetuar a própria separação entre cultura e trabalho, o caráter cindido da práxis humana, conforme foi definido na origem da sociedade. "O combate à cultura de massa só pode consistir em assinalar sua conexão com a persistência da injustiça social" (Horkheimer, apud Prismas). No capitalismo, a possibilidade de desfrutar da cultura, cultivar o próprio modo de ser estendeu-se às massas. Entretanto, tornou-se uma paródia de si mesmo pois onde não envolve a distração, reveste-se de um caráter utilitário ou de prestígio social totalmente comprometido com as regras da economia mercantil. A cultura é matéria de tempo livre e continua separada da práxis produtiva do indivíduo.

Noutros termos, o trabalho conserva o aspecto coercitivo e, a cultura, é tratada de maneira improdutiva. Na verdade, é motivo de uma profissão, que procura divertir do trabalho, e não um momento integral e constante da própria autoconservação. As mercadorias e serviços culturais são, para a maioria, um sucedâneo da possibilidade de pesquisar, escolher e conduzir a própria vida segundo suas próprias intenções, de maneira realmente autônoma.

A separação entre trabalho e diversão que sucede à oposição entre cultura e arte bárbara esconde, portanto, o fracasso da cultura. A cultura pretendia superar aquela divisão e, com ela, a própria idéia de divertimento porque, em princípio, "as necessidades do público englobam ambos os aspectos: a exigência honrada de uma [arte] válida e o desejo turvo de evasão; e nenhuma reação isolada dele é suscetivel de ser subsumida em uma ou outra categoria". A crítica à indústria cultural conserva a referida pretensão submetendo essa partilha a um exame que não deve ser visto como uma tomada de posição em favor da cultura elevada mas, antes, como referencial teórico de "um método objetivo que consiste em determinar em cada ocasião, a partir da função e da natureza [da arte], até que ponto esta

13 ADORNO, T., HORKHEIMER, M. Sociologica. Madri: Taurus, 1966, p. 245. 
cumpre sua respectiva tarefa ou até que ponto sua humanidade se limita exclusivamente a dissimular o inumano" (Cinema, p. 171).

Conforme escreve Adorno, a condenação do kitsch e da indústria cultural "esconde um aspecto da barbárie, do mal-estar destruidor na civilização" (Estética, p. 77). As diversões populares costumam ser condenadas como uma forma degenerada da alta cultura. Entretanto quem as lastima está alimentando ilusões sobre a sociedade. $\mathrm{O}$ entretenimento barato é um testemunho menor do fracasso da referida cultura. O conceito de arte pura não existe a prion, surgiu pouco a pouco, no decurso de um processo marcado pela dominação, cujo fim - um dia - poderá fazer contudo com que se associe à brincadeira.

Os privilégios conservados pelas classes dominantes excluíram as camadas populares da possibilidade de terem uma formação, não lhes deixando senão o divertimento. Nesse sentido, elas têm toda a razão em se distrair durante o tempo em que não tem de lutar pela sobrevivência. $O$ entretenimento tem um conteúdo emancipatório

\footnotetext{
"Nós não podemos culpar as pessoas porque elas estão mais interessadas na esfera privada e no consumo do que na da produção. Este traço contém um elemento utópico. Na Utopia a produção não desempenha um papel decisivo ela é a terra do mel e do leite. Penso que é de profundo significado que a arte e a poesia sempre mostraram uma afinidade com o consumo."14
}

Desde o início dos tempos, o entretenimento e a arte leve foram expressão da barbárie, mas também de liberdade. Atualmente; continua a ser assim: o aparelho de televisão "oferece à dona de casa, apesar dos filmes destinados a integrá-la, um refúgio onde ela pode passar algumas horas sem controle, assim como outrora, quando ainda havia lares e folgas vespertinas, ela podia se pôr à janela para ficar olhando a rua". 15

"A argumentação social diretamente dirigida contra a indústria cultural possui componentes ideológicos" (Estética, p. 29), porque a esfera da alta cultura é mediada pela diversão e, mais, todas as obras de arte, em alguma medida, sempre estiveram contaminadas pelos esquemas mercantis da indústria (Cf. Culture Industry, p. 106). "O elemento do desvario e do burlesco" está contido de maneira sublimada "mesmo nas obras mais importantes" (Estética, p. 139) assim como "os refúgios da arte circence que perdeu a alma [os produtos culturais] ... [ainda] representam o humano contra o mecanismo social" (Dialética, p. 134).

A separação entre as esferas da cultura superior e da arte bárbara é produtc de um processo histórico mas, por isso mesmo, algo que não é absoluto. " $\mathrm{O}$ kitscl mais miserável e que, no entanto, se apresenta necessariamente como arte, nãc pode impedir o que ele detesta, o momento do em-si, a pretensão à verdade' enquanto, por outro lado, "mesmo na obra superior se encontra oculto, sublimado até à sua autonomia, o momento do para-outro, algo que busca o residuo terreno da aprovação [social]" (Estética, p 345).

14 HORKHEIMER, apud JAY. The dialectical imagination. Berkeley (CA): University of California Press, 1996, p. 213.

15 ADORNO, T., HORKHEIMER, M. Dialética do esclarecimento. Rio de Janeiro: Zahar, 1985, p. 130. 
O conteúdo de verdade dos vários meios de expressão se modifica de maneira histórica. O kitsch pode tornar-se arte, assim como a arte pode tornar-se kitsch. A crítica não deveria condenar a diversão, porque teria um caráter desnaturado, nem mistificar a arte, porque é feita fora das regras. Conforme escreve Adorno, "Mahler's music is great not in spite of the kitsch toward which tend", mas por causa da maneira como sua construção solta a língua do kitsch, liberando o desejo que o comércio explora e que em troca o kitsch serve."16

Devemos a Andreas Huyssen uma análise seminal dessa conexão insuspeita entre os conceitos de arte e indústria cultural, conforme ela pode ser extraída do ensaio de Adorno sobre Wagner. Segundo o autor, o referido livro pode ser lido como um relato sobre o nascimento do fascismo do conceito de obra de arte total mas também do espírito da cultura de massa de uma das expressões artísticas mais ambiciosas do século passado. Resumidamente, Adorno sugere nessa análise que a cultura de mercado não se impõe à arte apenas do exterior: a própria arte se revela portadora de seus motivos, à medida que se emancipa das formas de arte tradicional.

Richard Wagner conta-se entre os criadores de obras de arte puras e, no entanto, praticava a indústria cultural, na medida em que, embora autônomas, suas obras, como as de outros, ${ }^{17}$ articulam seus conceitos principais como fantasmagorias. Significa que em suas óperas os materiais estéticos são elaborados de maneira regressiva. A técnica artística serve para criar um refúgio onde a consciência pode encontrar abrigo, ao invés de fazer frente aos problemas que os referidos materiais colocam historicamente. As experiências constitutivas da cultura de massa - fetichismo, reificação, regressão, mito - não somente se encontram contidas em embrião como são elaboradas de maneira que preludia a indústria cultural do século XX.

Contrariamente a Mahler, Wagner não logrou articular em sua música as rupturas culturais de seu tempo, esforçando-se por preservar sua autonomia, virtualmente condenada, através da criação de uma falsa harmonia que, de fato, apresenta-se como uma tentativa de retorno à mitologia. Cedendo às forças mercantis com que suas obras tinham de lidar, o artista "escondeu o crescente estranhamento do compositor perante o público ao conceber sua música como gesto impressionante e cooptar a audiência para suas obras através de efeitos calculados". ${ }^{18}$

As considerações externadas acima obrigam a critica à indústria cultural a matizar seus juízos negativos porque, seus criadores tendo visto ou não, também essa indústria tem, portanto, sua dialética. A pretendida integração estética da esferas da cultura e barbárie não exclui momentos em que reluzem meios de corrigir a seriedade da obra de arte negativa, nem a possibilidade de se proceder a uma verdadeira conciliação entre ambas. Os processos sociais que dão forma à

16 ADORNO, apud SCHÖNHERR, U. "Adomo and Jazz". In: Telos 87 (85-96) 1987, p. 95. Cf. Mahler. Barcelona: Peninsula, 1987.

17 Tchaikovsky, Maeterlinck e Wilde (Estética, p. 268) conceberam modelos e "serviram à indústria da cultura antes mesmo de ela encontrar seus verdadeiros consumidores" (ADORNO, T. Quasi una fantasia. Paris: Gallimard, 1978, p. 48-49).

18 HUYSSEN, A. After the great divide. Bloomington (IN): Indiana Univ. Press, 1986, p. 36. 
cultura de massa influenciam até mesmo as obras de arte com mais alta ambição. Mas então a recíproca é verdadeira. Os procedimentos artísticos em princípio podem se fazer presentes na cultura de mercado. A esfera do kitsch por certo não pode dar lugar a obras negativas mas o mesmo não vale para o caso de obras bem sucedidas esteticamente.

Deborah Cook baseia-se em Adorno para afirmar que as mercadorias culturais eventualmente podem satisfazer necessidades sociais que transcendem ou escapam ao contexto da sociedade capitalista. A produção artística e literária voltada para o mercado se caracteriza por renunciar à sua autonomia e apresentar-se sob a forma de bens de consumo que satisfazem necessidades previamente estabelecidas. Entretanto, conviria notar que esses bens possuem diversos graus de reificação.

Conforme explica a autora "o fato de que os estágios iniciais do processo de trabalho cultural possuem certos aspectos artesanais permite que alguns produtos menos padronizados e enfeitiçados possam chegar ao mercado - embora a formatação, excessivamente inclinada a imitar os produtos bem sucedidos, contribua para neutralizar essa possibilidade". ${ }^{19}$

Para Adorno, as obras de arte modernas eram as que não somente logravam resistir à reificação - exibindo em suas formas as contradições do capitalismo que se deseja suprimir da consciência, mas - ainda - conseguiam remeter as demandas não atendidas pelo sistema para fora do seu horizonte. A estratégia para tanto consistia em criar um feitiço capaz de romper o fetichismo e, assim, proceder à negação do seu caráter de mercadoria. ${ }^{20} \mathrm{O}$ conceito de indústria cultural exclui em si mesmo essa alternativa mas não a de produzir obras bem sucedidas. Considerando que o caráter mercantil é uma condição de verdade da obra de arte e se é verdade que a mercadoria pervade sua estrutura sem privar-lhe de força, podemos perguntar por que, então, a indústria cultural não poderia dar lugar a obras de arte ou, para usar um termo mais brando, bons produtos (Dieter Prokop).

Adorno chegou a escrever que "a indústria cultural possui seu momento de verdade em satisfazer uma necessidade substancial, proveniente da recusa socialmente intensificada [à felicidade]", acrescentando em seguida porém que "mediante o seu tipo de concessão, ela torna-se na inverdade absoluta." A promessa contida no projeto da formação estética do homem era uma utopia porque conflitava abertamente com a realidade. As mercadorias culturais da indústria são ideologia porque suas agências não cumprem o que prometem e ao mesmo tempo deixou de ser utópico: uma sociedade não mutilada pela mentalidade utilitária, o trabalho alienado e a disputa pelo poder econômico. "A felicidade encontrada

19 COOK, D. The culture industry revisited. Lanham (ML): Rowman and Littlefield, 1996, p. 103. Embora se esboce um processo de divisão do trabalho no âmbito das empresas musicais, "não se deve comparar de maneira muito literal o modo de produçāo da música ligeira que enseja produtos massivos com a produção de massa industrial" porque "o procedimento permanece por assim dizer artesanal e, em última instância, não se chega à racionalização total" (Introduzione a la sociologia della musica. Turim: Einaudi, 1971, p. 37-38).

20 ZUIDERVAART, L. Adorno's aesthetic theory. Cambridge (MA): MIT Press, 1991, p. 88-89. Para nós Cook confunde o conceito de obra de arte autônoma com o de obra de arte moderna (op. cit., p. 124-125). O problema deve ser tratado a partir da distinção adomiada entre Stravinski e Schoenberg (Filosofia da nova música. São Paulo: Perspectiva, 1974). 
através de indústria cultural é simplesmente substituto e falsidade na medida em que, referindo-as sempre ao estado de coisas que provoca sua falta, consiste na verdade em processo pelo qual se planifica e explora a necessidade de felicidade" (Estética, p. 342).

Entretanto, em parágrafo pouco notado de sua Teoria estética (p. 344-346) o filósofo observa que, detrás da rígida dicotomia entre cultura elevada e arte bárbara, "esconde-se um preconceito cultural". Certamente, há boa música medíocre, como há música boa e, no entanto, medíocre, a exemplo do que ocorre no mundo das letras e em outros gêneros artísticos. O primeiro caso ocorre com os chamados clássicos populares (evergreens), canções massivas que parecem não envelhecer $\mathrm{e}$ que superam os ciclos da moda (Imagine, de John Lennon, por exemplo). Os clássicos populares sem dúvida resultam de um processo de seleção mercantil mas, ao mesmo tempo, possuem uma força estética própria que lhes permite distinguir-se dos produtos comuns e conservarem-se vivos perante o público durante extenso período de tempo, a ponto de "o idioma corrente se tornar em produtos desse tipo uma segunda natureza que comporta algo similar à espontaneidade, à genuína idéia melódica". 21

A explicação para tanto pode ser buscada no fato de que, devido à pressão do mercado, as empresas culturais empregam muitos talentos autênticos que nem mesmo nesse campo podem ser anulados de todo: inclusive na fase avançada da comercialização se encontram idéias de primeira mão e lances de genialidade. 0 principal em relação ao ponto, porém, é a conclusão que dele podemos extrair e que se expressa no juízo segundo o qual "não faltam obras que, através de formulações informais, podendo ir do simples esboço até ao decalque, e também através da ausência de estruturação em favor do efeito calculado, têm o seu lugar na esfera da circulação estética subalterna e que, no entanto, a ultrapassam graças a qualidades sutis" (Estética, p. 345). ${ }^{22}$

As mercadorias culturais às vezes podem constituir um refúgio legítimo dos caracteres que a arte séria obrigou-se a renunciar, para poder continuar sobrevivendo, especialmente a comunicação com o público e a pretensão de validade universal. "As poucas canções de massa realmente boas - por exemplo - são um protesto contra o que a música de arte, tornada medida de si mesma, perdeu e não tem como compensar voluntariamente". ${ }^{23}$ Resumidamente, o significado disso é que o conteúdo de verdade dos vários meios de expressão se modifica de maneira histórica. Os conceitos a seu respeito não são critérios de sentido irremovíveis e, por isso, "o que originalmente foi previsto para o consumo, atua por vezes, perante o consumo superiormente racionalizado, como modelo de humanidade" (Estética, p. 344).

Segundo Dieter Prokop, responsável pela exploração dessa hipótese, experiências dessa ordem podem ser encontradas no que chama de bons produtos. As mercadorias culturais não precisam ser necessariamente padronizadas: eventualmente são desenvolvidas através de símbolos e formas progressivas.

21 ADORNO, T. Introduzione a la sociologia della musica, p. 43-45.

22 Adomo exemplifica o caso com os romances de Collete.

23 ADORNO, T. Introduzione a la sociologia della musica, p. 45. 
"Nem sempre são grandes obras de arte mas apresentam-se como produtos autônomos: são, na sua elaboração estética, mais conseqüentes e mais consistentes. Seu conteúdo é freqüentemente menos estereotípico ou então os estereótipos da cultura de massa the são inseridos conscientemente. Nesses produtos, a fascinação não parte de momentos que se preocupam com o bem-estar e o equilibrio psíquico. A fascinação - freqüentemente desagradável e até ameaçadora - resulta nesses produtos do fato de que o objeto apresentado e investigado é tratado de forma adequada a sua realidade ou suas possibilidades." 24

As contradições do objeto de trabalho estético não são submetidas a uma padronização, mas analisadas de acordo com suas próprias exigências e densidade, possibilitando o desenvolvimento de uma obra até certo ponto autônoma. O público é mantido a certa distância do produto: não se aprova de maneira mecânica seu padrão de gosto e preferência estética. As técnicas comumente empregadas para explorar o mercado são colocadas a serviço de uma atitude reflexiva, como ocorre com a técnica artística stricto sensu, ao menos segundo a visão de Adorno. ${ }^{25}$

"A montagem da sensibilidade e da expressão, contrastada com aquilo que é falsamente afirmado [na mensagem], [pode se tomar] um meio para tornar a ideologia social perceptivel e visualizável ao espectador, que exerce um acompanhamento competente, e para tornar conscientes desejos e utopias: para refleti-las e tomar claras as racionalizaçōes." 26

$\mathrm{Na}$ sociedade de massas, a tendência das pessoas é rejeitar as experiências que procuram transcender o fetichismo da mercadoria, preferindo-se os produtos esquemáticos, que não colocam risco de dissonância à recepção. Os referidos esquemas todavia não estão blindados ao emprego criativo. As convenções da arte de massas também podem ser usadas para pôr em discussão essa tendência, questionar o lazer acomodatício, enfim sacudir com a reificação da experiência.

Theodor Adorno conferiu um sentido demasiado negativo à prática da indústria cultural não porque esta carecesse de contradições mas, antes, porque essas contradições tendiam a ser reproduzidas através da canalização da espontaneidade não reprimida em sentido regressivo. Destarte, porém, ele se viu impedido de pesquisar a extensão e os propósitos com os quais "os produtos da indústria cultural poderiam dirigir-se e ativar os impulsos pré-egóicos de uma outra maneira". ${ }^{27}$

As perspectivas de análise da indústria cultural que se descortinam dessa forma de todo jeito são amplas e estão largamente por explorar, devendo merecer crescente atenção à medida que os processos culturais em curso diante de nossos olhos mais e mais colocam ao pensamento o problema de saber se e em até que ponto a cultura de mercado não está levando à supressão da própria obra de arte

24 PROKOP, D. Sociologia (Org. de Ciro M. Filho). São Paulo: Ática, 1986, p. 154. Exemplos de bons produtos podem ser descobertos nas chamadas produções altemativas. Entretanto, nada impede que elas apareçam também nos circuitos massivos.

PROKOP, D. Sociologia, p. 115. O pesquisador desenvolve a análise levando em conta os filmes de Griffith. A moralidade "não aparece simplesmente do filme como lição, que se leva para casa em palavras e ações, mas resulta da análise artística conseqüente daquilo que o objeto estudado por si mesmo pretende ser. Ela teria efeito plausível antes de mais nada por meio disto e só em segundo plano como mensagem" (p. 62-63). 
moderna ou se, ao contrário, a oposição que surgiu entre elas por volta da virada do século ainda continua sendo válida.

A possibilidade de se criarem obras de arte negativas por certo continua hoje tão aberta e incerta como foi desde o seu surgimento (Culture industry, p. 67). A crescente dificuldade em fornecer exemplos contemporâneos sem dúvida conta-se, porém, entre os fatores que têm levado vários herdeiros do pensamento frankfurtiano a defender a tese de que não somente não há mais uma distinção válida possível entre a arte séria e a arte kitsch - a hipótese da indústria cultural - como a reificação chegou a tal ponto que nenhuma obra mais tem como lhe fazer frente a produção cultural identificou-se totalmente com o processo de mercantilização. ${ }^{28}$

A matéria como um todo está aberta à discussão mas foge ao nosso escopo e competência. A possibilidade da última hipótese estar certa contudo é provocativa, sugerindo-nos que atualmente podemos estar assistindo a uma nova mudança na relação entre os vários meios de expressão. 0 resultado do progresso da indústria da cultura pode ser o surgimento de uma oposição entre bons e maus produtos que transcende a hierarquização mercadológica.

A circunstância dessa oposição ser vivida no âmbito de uma indústria cultural que perpassa todos os momentos da vida e de que o consumo de bons produtos por si só não leva a um mundo melhor - representa, no máximo, um de seus sinais, constitui razão suficiente para não nos iludirmos sobre seu sentido e conservarmos uma atitude crítica diante de seu processo de emergência. Atualmente, a reivindicação de um conteúdo crítico e antitético propende a cair no vazio, porque seu impulso se insere e conserva num contexto mais amplo que trabalha e se esforça pela sua neutralização.

Os individuos se encontram emocionalmente ligados não apenas aos produtos mas aos próprios esquemas da indústria cultural. O fenômeno engendrou uma situação em que exonerar-se dela significa, ao mesmo tempo, renunciar a uma forma líquida e certa de satisfação das necessidades subjetivas imediatas. ${ }^{29}$ Entretanto, o reconhecimento desse fato também não deveria nos fazer fechar os olhos para um fenômeno cujo próprio aparecimento questiona desde dentro a pretensa integração das esferas da arte de elite e da arte bárbara e recoloca o problema de sua reconciliação, expondo o caráter de ideologia da indústria cultural.

28 Segundo Jameson, "the Archimedean point of some 'genuinely aesthetic experience'[...] has disappeared" (Lat: Adorno. Nova York: Verso, 1990, p. 142). Confira a critica bastante justa feita a essa idéia por Lambert Zuidevaart (Adorno's aesthetic theory, p. 257-274).

29 ADORNO, T. "Democratic leadership and mass manipulation" [1950]. In: Gesammelte Schriften [Vol 20]. Frankfurt: Suhrkamp, 1986, p. 271. 